\title{
Dextropropoxyphene (Distalgesic) overdosage in the West Midlands
}

\author{
R M WHITTINGTON
}

British Medical fournal, 1977, 2, 172-173

I wish to draw attention to the acute danger of overdosage with the analgesic drug dextropropoxyphene, which is most commonly prescribed in Britain as Distalgesic (paracetamol $325 \mathrm{mg}$ and dextropropoxyphene hydrochloride $32.5 \mathrm{mg}$ ). The fatal results from taking this drug are becoming apparent to forensic toxicologists, but medical practitioners may not be so aware of the dangerous consequences of overdosage. ${ }^{1}$ I present the picture as I see it in Birmingham and the West Midlands.

\section{Case details}

During the past three years, 26 deaths due to Distalgesic have been investigated by the Home Office Forensic Science Laboratory, Birmingham. Some were suicidal, but many were more in the nature of "cris du coeur." All died at home except one, when the overdose was taken in hospital. In 12 cases an appreciable amount of alcohol was an additional factor. It is interesting that the average age at death was $36 \cdot 1$, whereas the average for all types of overdose was $57 \cdot 4$, thus emphasising the danger for younger people. Distalgesic is currently the commonest cause of death in those cases of drug overdose referred to the forensic science laboratory. For instance, during this period, they have only done analyses on three fatal cases of paracetamol overdosage alone, compared with the 26 due to Distalgesic.

A different picture, however, emerges from hospital practice. Last year, the West Midlands Regional Toxicology Laboratory analysed 222 paracetamol overdoses of which two patients subsequently died of hepatorenal failure. In contrast, there were 60 cases of Distalgesic overdosage, none of which were associated with alcohol, and none of whom died. The number of tablets taken were known to vary from two to 40 . All these came from various hospitals in the West Midlands region.

A striking feature in the 26 overdose cases at the forensic science laboratory is that in these cases, when the time interval between ingestion of the Distalgesic and death was known, death occurred very rapidly. The amount of overdose seems to vary, but is commonly estimated to be in the range of 20 to 30 tablets.

\section{DANGERS OF ALCOHOL}

In the Birmingham Coroner's Court we have recently held six inquests on cases of Distalgesic overdose, again mostly in young people (see table). In addition, a healthy girl of 14 was recently found dead in her bed with a characteristic cyanotic discolouration after it was known that she had been out with an older man and had drunk

Coroner's Court, Birmingham B4 6NE

R M WHITTINGTON, DMJ, MRCGP, HM Coroner for district of Birmingham three whiskies. A specific inquiry was made into the availability of Distalgesic because of the sudden respiratory failure associated with the recent consumption of alcohol. This revealed that she was menstruating and suffered from dysmenorrhoea, and that tablets were missing from her elder sister's bottle of Distalgesics, prescribed for a similar condition. An excess of paracetamol and dextropropoxyphene was found in the stomach contents. Results of detailed analyses and the inquest are awaited. These seven cases show the rapidity of the fatal outcome, and this would probably be due to the known respiratory depressive effect of the dextropropoxyphene element in Distalgesic tablets. Alcohol (and other sedative drugs) would have an additive effect. Distalgesic is a drug that is acceptable to patients and, certainly, it is effective in pain relief.

The Extra Pharmacopoeia (Martindale) ${ }^{2}$ refers to it as having an analgesic effect of a little less than that of codeine. In overdosage, however, shallow slow respiration and respiratory depression are described. It is interesting that with those patients who were admitted to hospital after an overdose, the main problem seems to be the onset of acute hepatic failure due to the paracetamol constituent. The stage of serious respiratory depression due to dextropropoxyphene has usually passed and so is not observed if the subject survives to obtain treatment in hospital.

There have been other reports of the rapid death in overdosage with Distalgesic-for instance, there was a series from the American Army in Germany in which 13 young servicemen died from overdosage. ${ }^{3}$ In all these fatalities the drug was taken by mouth, and death occurred within 30 to 45 minutes, sometimes with associated convulsions. In eight of these cases alcohol was taken as well. Nearer home Carson and Carson ${ }^{4}$ have reported that in three years they have investigated 30 rapid deaths in Belfast, which they were convinced were due to dextropropoxyphene, and they again emphasised the danger of taking Distalgesic with alcohol. It would seem that the dextropropoxyphene portion of Distalgesic and not the paracetamol is responsible for the sudden deaths.

\section{Lack of usual side effects}

Distalgesic is a drug that is growing in use because it is free of many of the unwanted side effects of other common analgesics. This increase is apparent in the Midlands, and in one Birmingham general hospital the dispensing of Distalgesic increased by $35 \%$ last year. A local warehouse supplying retail chemists and prescribing doctors despatched $27 \%$ more Distalgesic tablets than the year before and a central Birmingham retail pharmacist told me that their dispensing rate for the product had increased by half in the past year.

A recent advertisement for Distalgesic recommends it "for everyday aches and pains"5 and, in a review of mild analgesic drugs, Sampson Lipton ${ }^{6}$ describes Distalgesic as an effective combination and one that is liked by patients and is a useful alternative to paracetamol with its danger of liver failure in overdosage. Likewise, in World Medicine, ${ }^{7}$ in a discussion of the drug control of common symptoms, Distalgesic was recommended for mild pain and is described as an equivalent alternative to soluble aspirin or paracetamol.

Thus a popular belief is developing that Distalgesic is a safe analgesic that may be prescribed with increasing frequency, often at doses above those recommended by the manufacturers-that is, two tablets three or four times a day. The third case in my table shows this, as 
TABLE-Details of cases of Distalgesic overdosage from the Birmingham District Coroner's Court

\begin{tabular}{|c|c|c|c|c|c|}
\hline Age and sex & $\begin{array}{l}\text { Blood alcohol } \\
\text { or other drugs }\end{array}$ & $\begin{array}{l}\text { Estimated overdosage } \\
\text { (tablets) }\end{array}$ & Source of tablets & $\begin{array}{l}\text { Time to fatal onset } \\
\text { (hours) }\end{array}$ & Verdict \\
\hline $26(F)$ & $\begin{array}{l}280 \mathrm{mg} / 100 \mathrm{ml} \\
\text { No other drugs }\end{array}$ & 15 & $\begin{array}{l}50 \text { tablets prescribed } \\
16 \text { days before death }\end{array}$ & 1 & Killed herself \\
\hline $33(M)$ & Nil & 40 & Prescribed for mother & Considerably less & Killed himself \\
\hline $29(M)$ & Nil & 30 & $\begin{array}{l}100 \text { tablets (three four-hourly) } \\
\text { prescribed by GP for } \\
\text { sinusitis }\end{array}$ & $\operatorname{tnan}<2$ & Killed himself \\
\hline $20(M)$ & $\begin{array}{l}145 \mathrm{mg} / 100 \mathrm{ml} \\
\text { No other drugs }\end{array}$ & $20-30$ & $\begin{array}{l}\text { sinusitis } \\
\text { Prescribed for friend }\end{array}$ & 5 & $\begin{array}{l}\text { Open verdict. } \\
\text { Intention uncertain }\end{array}$ \\
\hline $\begin{array}{l}25(M) \\
47(\mathrm{~F})\end{array}$ & $\begin{array}{l}\text { Nil } \\
\text { Alcohol nil. } \\
\text { Quinalbarbitone } \\
400 \mathrm{mg}\end{array}$ & $\begin{array}{l}40-45 \\
10-20\end{array}$ & $\begin{array}{l}\text { Not known } \\
60 \text { prescribed for self } \\
3 \text { days before }\end{array}$ & $\begin{array}{r}\text { Uncertain } \\
<6\end{array}$ & $\begin{array}{l}\text { Killed himself } \\
\text { Killed herself }\end{array}$ \\
\hline
\end{tabular}

the dosage prescribed was up to 18 tablets to be taken a day-more than twice the manufacturers' recommended maximum dose. Both doctors and patients, therefore, may be lulled into a false sense of relative complacency over the taking of this drug. For instance, to take 20 aspirins may not be disastrous, but an equal number of Distalgesics may kill in a very short time. The manufacturers themselves state in their latest data sheet ${ }^{*}$ that the product in serious overdosage is narcotic and provokes respiratory depression, and this may be additive with alcohol. Dependence with dextropropoxyphene has been reported and overdosage symptoms are indeed similar to morphine with the addition of convulsions.

The very real dangers from overdosage with products containing dextropropoxyphene, particularly when taken with alcohol, are becoming clear to forensic toxicologists but may not be appreciated by clinicians, as the unfortunate people, often young and healthy, who take these drugs, whether intentionally to kill themselves or not, often die rapidly at home before they are found and so never reach hospital for treatment. Prescribing physicians, therefore, should remember the potential toxicity when considering to whom to prescribe dextropropoxyphene, the dosage advised, and the quantity to be dispensed.

I am indebted to the Director of the Home Office Forensic Science Laboratory, Birmingham, and $\mathrm{Mr} \mathrm{W}$ B Yeoman, Director of the Regional Toxicology Laboratory, Dudley Road Hospital, Birmingham, for information used in preparing this article.

\section{References}

${ }^{1}$ British Medical fournal, 1977, 1, 668.

2 Martindale-Extra Pharmacopoeia, 26th edn, 1972, 1112.

3 Tennant, F S, Archives of Internal Medicine, 1973, 132, 191.

${ }^{4}$ Carson, D J L, and Carson, E D, British Medical fournal, 1976, 2, 105.

5 Pulse, 1977, 34, 39.

6 Lipton, S, Practitioner, 1975, 215, 461.

7 World Medicine, 1976, 11, 17.

${ }^{8}$ Data Sheet Compendium, 1977, 219.

(Accepted 14 April 1977)
Medical Gastroenterological Department C, Herlev University Hospital, DK 2730 Herlev, Denmark

POVL RIIS, MD, physician-in-chief, professor of internal medicine the protection of the research subject while not inhibiting medical research unnecessarily.

\section{Helsinki Declaration II}

Among the important paragraphs of Helsinki Declaration II are those stating that the declaration covers not only treatment, but also diagnoses and prophylaxis and those that make a written research protocol obligatory; emphasise that ethical aspects of biomedical research should always be included in a report; emphasise the patients' and other research subjects' right to decide (via informed consent) whether to join the project or not; accept the use of control groups as a necessary tool of the controlled trial; realise that clinical research can never guarantee a result beneficial to the patients participatingbut only a potential gain; and, probably most important, demand that the research protocol, if man is the scientific object, be referred (paragraph 12 2) to an independent committee "for consideration, comment, and guidance."

The Danish Medical Association, as one of the Nordic 